\title{
Psychopathology and Borderline Personality Pathology Associated with Lifetime Self-Injurious Behavior in Adolescent
} Psychiatric Inpatients and Detainees

\author{
Julian Koenig ${ }^{1}$, Romuald Brunner²,3, Johannes Michael Schmidt², Peter Parzer², \\ Franz Resch ${ }^{3}$, and Michael Kaess ${ }^{1,3,4}$
}

\author{
Section for Translational Psychobiology in Child and Adolescent Psychiatry, Clinic for Child and Adolescent Psychiatry, \\ Centre for Psychosocial Medicine, University of Heidelberg, Germany \\ Section for Disorders of Personality Development, Clinic for Child and Adolescent Psychiatry, Centre for Psychosocial Medicine, \\ University of Heidelberg, Germany \\ Clinic for Child and Adolescent Psychiatry, Centre for Psychosocial Medicine, University Hospital Heidelberg, Germany \\ University Hospital of Child and Adolescent Psychiatry and Psychotherapy, University of Bern, Switzerland
}

\begin{abstract}
Objective: Self-injurious behavior (SIB) is a widespread phenomenon among adolescent psychiatric inpatients. It is also reported among delinquent adolescents detained in correctional facilities. While previous studies have addressed different functions of SIB within offender populations, here we investigate particular patterns of borderline personality pathology and psychopathology underlying SIB in both adolescent psychiatric inpatients and detainees. Method: Adolescent psychiatric inpatients and detainees were recruited consecutively. Participants completed self-reports on SIB, suicidal thoughts and behavior, borderline personality pathology, and general psychopathology. Predictors of lifetime SIB by group were analyzed. Results: Psychiatric inpatients $(n=77)$ and detainees $(n=50)$ did not differ with respect to lifetime SIB $(57.14 \%$ versus $54.00 \%)$, whereas SIB within the past year did $\left(67.53 \%\right.$ versus $\left.14 \% ; \chi 2_{(1)}=6.158, p=.013\right)$. Psychiatric inpatients reported greater emotional problems $\left(t_{(125)}=5.109, p<.0001\right)$ and greater borderline personality pathology. Those with lifetime SIB were characterized by greater emotional problems and borderline personality pathology, independent of their group. Results from regression analyses suggest no group-specific predictors of lifetime SIB. Conclusions: Although psychiatric inpatients endorse greater psychopathological distress, lifetime SIB among adolescent psychiatric inpatients and detainees is associated with similar patterns of psychopathology and borderline personality pathology.
\end{abstract}

Keywords: self-injurious behavior, delinquency, detainees, borderline personality pathology, psychopathology

\begin{abstract}
Die Psychopathologie und Borderline-Persönlichkeitspathologie lebenslangen Selbstverletzungsverhaltens bei jugendlichen psychiatrischen PatientInnen und Häftlingen

Hintergrund: Selbstverletzendes Verhalten (SVV) ist ein häufiges Phänomen bei Jugendlichen, insbesondere im Kontext der psychiatrischen Versorgung. SVV wird häufig auch von Jugendlichen im Jugendarrest berichtet. Während vorhergehende Studien die Funktionen von SVV im Strafvollzug untersuchten, war das Ziel der vorliegenden Studie, potentielle Unterschiede hinsichtlich der mit SVV assoziierten, psychopathologischen Belastung und Borderline-Persönlichkeits-Pathologie von Jugendlichen im Kontext der psychiatrischen Versorgung und dem Jugendarrest zu identifizieren. Methodik: Jugendliche Patienten und Inhaftierte im Jugendarrest wurden konsekutiv für eine Teilnahme an der Studie rekrutiert. Alle Teilnehmer füllten Fragebögen zu SVV, Suizidalität, Borderline-Persönlichkeits-Pathologie und Psychopathologie aus. Prädiktoren von Lebenszeit SVV wurden in Abhängigkeit der Gruppenzugehörigkeit analysiert. Ergebnisse: Jugendliche Patienten $(n=77)$ und Inhaftierte im Jugendarrest $(n=50)$ unterscheiden sich nicht hinsichtlich der Lebenszeitprävalenz von SVV ( $57.1 \%$ versus $54.0 \%)$, jedoch bezüglich der Häufigkeit von SVV im letzten Jahr (67.5\% versus $14.0 \% ; \chi^{2}(1)=6.158, p=.013$ ). Patienten berichten im Vergleich zu Inhaftierten im Jugendarrest von vermehrt emotionalen Problemen $\left.t_{(125)}=5.109, p<.0001\right)$ und stärker ausgeprägter Borderline-Persönlichkeits-Pathologie. Jugendliche mit Lebenszeit SVV berichten unabhängig von der Gruppenzugehörigkeit vermehrt von emotionalen Problemen und stärker ausgeprägter Borderline-Persönlichkeits-Pathologie. Schlussfolgerung: Während jugendliche Patienten vermehrt psychopathologische Auffälligkeiten zeigen, ist Lebenszeit SVV bei psychiatrischen Patienten und Inhaftierten im Jugendarrest dieser Altersklasse mit vergleichbaren Mustern psychopathologischer Belastung und Borderline-Persönlichkeits-Pathologie assoziiert.
\end{abstract}

Schlüsselwörter: selbstverletzendes Verhalten, Jugendarrest, Strafvollzug, Borderline-Persönlichkeitspathologie, Psychopathologie 


\section{Background}

Self-injurious behavior (SIB) is defined as the intentional, self-directed act of injuring one's own body tissue by cutting, burning, etc., regardless of suicidal intent (Brunner et al., 2014). It includes both nonsuicidal self-injury (NSSI), which was recently introduced in the $5^{\text {th }}$ version of the Statistical and Diagnostic Manual of Mental Disorders (DSM-5) under section 3 (American Psychiatric Association, 2013) as a disorder warranting further research, and deliberate selfharm (DSH, i.e., self-damaging acts both with or without suicidal intent). SIB is a widespread phenomenon, in particular among adolescents. Meta-analytical evidence points to a lifetime prevalence of occasional SIB at $16 \%$ to $18 \%$ in samples of nonclinical adolescents (Muehlenkamp, Claes, Havertape, \& Plener, 2012; Swannell, Martin, Page, Hasking, \& St John, 2014). Prevalence estimates vary between $50 \%$ and $80 \%$ among psychiatric inpatients in this age group (Kaess et al., 2013; Plener et al., 2016; Zetterqvist, 2015). Given its prevalence, and given the association with suicide attempts (Asarnow et al., 2011; Prinstein et al., 2008; Tang et al., 2011; Wilkinson, Kelvin, Roberts, Dubicka, \& Goodyer, 2011) and mortality (Hawton \& Harriss, 2007), the World Health Organization (2014) has recognized SIB as one of the top five major health threats to adolescents.

While frequent among psychiatric inpatients, SIB is also reported among delinquent prisoners. A recent population-based study in Sweden found that SIB is associated with an increased risk for conviction for a violent offense independent of sex (Sahlin et al., 2017). Likewise, a large epidemiological survey on SIB in prisons in England and Wales found annual prevalence rates of SIB to lie around 5-6\% among male and 20-24\% among female prisoners (Hawton, Linsell, Adeniji, Sariaslan, \& Fazel, 2014). Based on data provided by the UK Ministry of Justice, the annual prevalence of SIB among prisoners during the time of detention is rising (UK Ministry of Justice, 2015). Data from other European countries are limited, with one study from Italy (Carli et al., 2010, 2011) reporting lifetime SIB among $17 \%$ of a large adult prison sample. Studies addressing the prevalence of SIB within the youth justice system are scarce. Data from Japan suggest that $16.4 \%$ (cutting) to $35.8 \%$ (burning) of delinquent adolescents detained in prisons endorse lifetime SIB (Matsumoto et al., 2005). A review of the existing literature estimates the lifetime prevalence of SIB among adolescents detained in juvenile correctional facilities to be between $6.2 \%$ and $44 \%$ (Casiano, Katz, Globerman, \& Sareen, 2013), and another recent review concludes that adolescent detainees have a 16- to 18-fold higher risk of suicidal behavior and suicide compared to the general population (Radeloff et al., 2016). A well-powered recent study conducted in Switzerland reports lifetime prevalence rates of occasional and repetitive
NSSI at $21.9 \%$ and $18.4 \%$, respectively (Lüdtke et al., 2017). Prevalence estimates for SIB among delinquent adolescents during the time of detention range between $10 \%$ (limited to males; Chowanec, Josephson, Coleman, \& Davis, 1991) and $30 \%$ (Penn, Esposito, Schaeffer, Fritz, \& Spirito, 2003). An Australian study found SIB in around $9 \%$ of young offenders during the past year (Kenny, Lennings, \& Munn, 2008). Episodes of SIB within the prison setting were previously attributed to stress associated with imprisonment and different coping typologies to deal with this situation (Kirchner, Forns, \& Mohíano, 2008). This notion is further supported by studies illustrating that, among adolescent offenders, $75 \%$ of lifetime acts of SIB actually occurred in prison (Kenny et al., 2008).

From adolescent population-based and psychiatric samples it is known that SIB is associated with psychopathology across axis I and axis II (Auerbach et al., 2014; Brunner et al., 2014). Although SIB is a core characteristic feature of borderline personality disorder (BPD) (Kaess et al., 2016), it is also associated with a variety of other psychopathological disorders. Most frequently, affective disorders, including depression and anxiety, and emotion deficits (Thomassin, Quint, Sezlik, \& Shaffer, 2017) are associated with SIB (Fliege, Lee, Grimm, \& Klapp, 2009; Madge et al., 2011; Müller, Claes, Smits, Brähler, \& Zwaan, 2016), together with ADHD and conduct disorder in adolescents (Hawton, Saunders, Topiwala, \& Haw, 2013). Psychiatric disorders, particularly depression (Fazel \& Seewald, 2012), are also common among prisoners (Fazel, Hayes, Bartellas, Clerici, \& Trestman, 2016) and adolescents in juvenile detention (Fazel, Doll, \& Långström, 2008). Similar to the psychiatric setting, SIB in incarcerated women seems to be associated with greater psychopathological distress (Roe-Sepowitz, 2007). Previous studies addressing psychopathology associated with SIB in delinquent adolescents underline the importance of affective disorders (e.g., Lüdtke et al., 2017), but included no clinical control group to address the specificity of certain domains of psychopathology in predicting SIB in this population.

Whereas previous studies addressed different functions of SIB within offender populations (for a review on NSSI in offender populations, see Dixon-Gordon, Harrison, \& Roesch, 2012), here we aimed to investigate particular patterns of borderline personality pathology and psychopathology underlying SIB in adolescent psychiatric inpatients and detainees. The present study the prevalence of lifetime SIB, comparing adolescent psychiatric inpatients and delinquent adolescents in detention units. Further, we explored potential differences in borderline personality and psychopathology underlying SIB in the respective groups. Based on the existing literature, we hypothesized that SIB is more frequent among psychiatric inpatients compared to delinquent adolescents recruited from detention units, al- 
though high frequency of SIB was also expected in adolescent detainees. Further, we hypothesized that the greater prevalence of lifetime SIB is associated with greater distress on affective domains as indicated by respective entities of psychopathology (i.e., depression and anxiety) and borderline personality pathology (i.e., affective lability).

\section{Methods}

\section{General Procedures}

Two independent samples were consecutively recruited at the Department of Child and Adolescent Psychiatry, Heidelberg University (inpatients) and a juvenile detention unit in Worms (detainees). The study was approved by the Rheinland-Palatinate Ministry of Justice and the institutional ethics committee at the Medical Faculty at Heidelberg University (study ID: S-299/2010). Written informed consent was obtained from all participants prior to their inclusion in the study. Legal guardians were informed about the study procedures. Participants at the Clinic for Child and Adolescent Psychiatry in Heidelberg received an allowance of $10 €$ for their participation. Because of restrictions with respect to the possession of money at the detention unit in Worms, participating delinquents received chocolate as compensation for their participation.

\section{Study Sites}

Consecutive recruiting was performed at both study sites between November 2010 and May 2011. Given the expectation that groups would significantly differ on age and sex, matched recruitment based on three age groups ( 14 to $\leq 16$; 16 to $\leq 18$, and 18 to 21 years) was performed where possible. Based on a previous consecutive sample recruited at the Clinic for Child and Adolescent Psychiatry in Heidelberg (Kaess et al., 2011), cell sizes for sex per age group were recruited among the detainee sample. Active recruitment at the Clinic for Child and Adolescent Psychiatry in Heidelberg took place between 1 November 2010 and 30 April 2011. Active recruitment at the detention unit in Worms took place between 8 November 2010 and 16 May 2011. All patients receiving inpatient or outpatient treatment at the Clinic for Child and Adolescent Psychiatry in Heidelberg during the recruitment period were contacted for participation in the study after consultation with the attending physician. Patients who were not contacted in person (i.e., outpatients) were recruited via telephone. A total of $N=77$ patients were recruited for participation in the study, of which $n=70$ (90.9\%) were inpatients and $n=7$
(9.1\%) patients from the dayclinic. All assessments were completed between 8 November 2010 and 7 June 2011.

According to German law, when adolescents ( $\geq 14$ years of age) or young adults (18 to 21 years of age) lack responsibleness or the capacity of discernment commit a crime, the criminal law relating to youth offenders is applied, which calls for corrective methods or other means of correction. This so-called Jugendarrest (i.e., detention of a juvenile delinquent) is not a formal custodial sentence. At the detention unit in Worms, $N=744$ adolescent delinquents (14 to 18 years of age) and young adults (18 to 21 years of age) were detained in 2011. Of these, $n=126(16.9 \%)$ were female and $n=618(83.1 \%)$ male. $N=45(6.1 \%)$ were $14-16$ years old ( $n=19$ or $42.2 \%$ of whom were female), $n=227(30.5 \%)$ were $16-18$ years old ( $n=44$ or $19.4 \%$ of whom were female), and $n=472(63.4 \%)$ were older than 18 years of age ( $n=63$ or $13.4 \%$ of whom were female). Among male delinquents, assault ( $n=151,24.4 \%)$, theft ( $n=135,21.8 \%)$, driving without a license $(n=71,11.5 \%)$, narcotics violations $(n=71,11.5 \%)$ and property crimes $(n=61,9.9 \%)$ were the most common delicts. Among female inmates, theft $(n=36$, $28.6 \%$ ), assault ( $n=22,17.5 \%)$, and fraud $(n=21,16.7 \%)$ were the most common charges. Delinquents were recruited for participation in the study during their detention. The detainees were preselected upon arrival at the detention unit based on sex in accordance with the clinical group recruited at the Clinic for Child and Adolescent Psychiatry in Heidelberg. A total of $n=50$ delinquents were recruited for participation in the study. Assessments were completed between 17 November 2010 and 18 May 2011.

\section{Assessments}

The Functional Assessment of Self-Mutilation (FASM) (Lloyd, Kelley, \& Hope, 1997; Lloyd-Richardson, Perrine, Dierker, \& Kelley, 2007) was used for the detailed assessment of SIB methods, frequency and functions within the past year. Besides a checklist on 11 different (e.g. cutting) or other SIB behaviors and their frequency within the past year, respondents are asked to indicate whether they had received medical treatment as a consequence of the behavior. In addition, we assessed lifetime SIB (i.e., any single SIB event in the past). The FASM repeatedly showed good psychometric properties in adolescents populations (Esposito, Spirito, Boergers, \& Donaldson, 2003; Guertin, Lloyd-Richardson, Spirito, Donaldson, \& Boergers, 2001; Penn et al., 2003). Suicidal thoughts and behavior were assessed using the Paykel Suicide Scale (PSS) (Paykel, Myers, Lindenthal, \& Tanner, 1974). Five items each were used to assess the lifetime prevalence of suicidal thoughts and behavior, ranging from considering life as not worth living to actual suicidal attempts. 
A modified short-form of the adolescent version (Tromp \& Koot, 2008) of the Dimensional Assessment of Personality Pathology - Basic Questionnaire (DAPP-BQ) (Livesley \& Jackson, 2009) in German (Pukrop, 2002; Pukrop, Gentil, Steinbring, \& Steinmeyer, 2001) - previously used in delinquent adolescents (Krischer, Pukrop, Halstenberg, Lehmkuhl, \& Sevecke, 2012; Krischer, Sevecke, Lehmkuhl, \& Pukrop, 2007) - was used to assess borderline personality pathology. Each of the 172 items is rated on a 5-point scale, assessing 11 dimensions of borderline personality pathology, including: affective lability (AL), anxiousness (ANX), cognitive dysregulation (CD), identity problems (IP), insecure attachment (IA), oppositionality (OP), submissiveness (SUB), narcissism (NAR), social avoidance (SA), self-harm (SH), and suspiciousness (SUS). Unlike the long-form of the DAPP-BQ, the present version does not assess the dimensions of callousness, compulsivity, conduct problems, intimacy problems, restricted expression, rejection, and stimulus seeking and is therefore reflective of borderline personality pathology in particular and not of personality pathology in general.

The self-report short version of the Strengths and Difficulties Questionnaire (SDQ) was used to measure emotional and behavioral problems (Goodman, 1997). There, 25 items are each rated on a 3-point scale. The items are divide by 5 scales: emotional symptoms (SMO); conduct problems (CON); hyperactivity/inattention (HYP); peer relationship problems (PER), and prosocial behavior (SOC).

\section{Statistical Analysis}

Group differences were investigated using two-sided independent-samples $t$-tests for continuous variables and chisquare $\left(\chi^{2}\right)$ tests for categorical variables. Potential predictors of lifetime SIB were analyzed using logistic regression with lifetime SIB (no/yes) as dependent variable and dimension of psychopathology (SDQ subscales) and borderline personality pathology (DAPP-BQ subscales) as independent variables. All logistic regression analyses were adjusted for group, sex, and age and further tested for a potential interaction of the predictor with group assignment, to reveal specific predictors for by group. All analyses were performed using Stata/SE (Version 14.0; StataCorp LP, College Station, TX, US) with $\alpha$ set to .05.

\section{Results}

The sociodemographic characteristics of the groups are given in Table 1. Compared to the sample of psychiatric inpatients, detainees were significantly older $\left(_{(125)}=-3.44\right.$, $p=.001)$. On average, detainees reported more delicts compared to inpatients $\left(t_{(125)}=-5.42, p<.0001\right)$, including assault $\left(\chi_{(1)}^{2}=8.98, p=.003\right)$, property offenses $\left(\chi_{(1)}^{2}=9.26\right.$, $p=.002)$, and other delicts $\left(\chi_{(1)}^{2}=4.81, p=.028\right)$. There were significant differences between groups regarding suicidality, with more frequent reports of suicidal thoughts and behavior among inpatients $\left(\chi_{(1)}^{2}=17.23, p=.004\right)$.

\section{Self-Injurious Behavior}

The groups did not differ with respect to the reporting of lifetime SIB, but SIB within the past year $\left(\chi_{(1)}^{2}=6.16\right.$, $p=.013)$. Among adolescent inpatients, $57.1 \%$ reported lifetime SIB compared to $54.0 \%$ among detainees. SIB within the past year was reported by $67.5 \%$ of inpatients and $14.0 \%$ of detainees. The groups did not differ with respect to the total number of past year SIB methods endorsed. Cutting $\left(\chi_{(1)}^{2}=5.07, p=.024\right)$, scraping $\left(\chi_{(1)}^{2}=12.83, p<.0001\right)$ or "erasing" $\left(\chi_{(1)}^{2}=4.63, p=.031\right)$ of the skin, hitting oneself

Table 1. Characteristics of the study sample by group. The $p$ values refer to differences between groups based on $\chi^{2}$ tests (categorical variables) or t-tests (continuous variables)

\begin{tabular}{|c|c|c|c|}
\hline & $\begin{array}{l}\text { Psychiatric } \\
\text { inpatients }\end{array}$ & Detainees & $p$ \\
\hline$N(\%)$ & $77(60.63)$ & $50(39.37)$ & \\
\hline Female (\%) & $46(59.74)$ & $27(54.00)$ & .523 \\
\hline Age, mean (SD) & $16.62(0.18)$ & $17.69(0.27)$ & $<.001$ \\
\hline \multicolumn{4}{|l|}{ Self-injury } \\
\hline Lifetime & $44(57.14)$ & $27(54.00)$ & .727 \\
\hline Past year & $26(67.53)$ & $7(14.00)$ & .013 \\
\hline \multicolumn{4}{|l|}{ Delict, $n(\%)$} \\
\hline Assault & $33(42.86)$ & $35(70.00)$ & .003 \\
\hline Property offense & $43(55.84)$ & $41(82.00)$ & .002 \\
\hline Other & $70(90.91)$ & $50(100)$ & .028 \\
\hline Count & $3.53(0.32)$ & $6.40(0.44)$ & $<.0001$ \\
\hline Suicidality, n (\%) & & & .004 \\
\hline Not suicidal & $14(18.18)$ & $17(34.00)$ & \\
\hline Life not worth living & $5(6.49)$ & $2(4.00)$ & \\
\hline Wish to die & $1(1.30)$ & $8(16.00)$ & \\
\hline Suicidal ideation & $14(18.18)$ & $8(16.00)$ & \\
\hline Serious suicidal ideation & $19(24.68)$ & $7(14.00)$ & \\
\hline Suicide attempt & $24(31.17)$ & $8(16.00)$ & \\
\hline
\end{tabular}


$\left(\chi_{(1)}^{2}=7.79, p=.005\right)$, and inserting objects under the skin $\left(\chi_{(1)}^{2}=4.09, p=.043\right)$ were more frequently reported by inpatients. Overall inpatients required more frequently medical treatment as a consequence of SIB within the past year, in particular after cutting their own skin $\left(\chi_{(1)}^{2}=4.71\right.$, $p=.030)$. The frequency of SIB over the past year, in participants who endorsed past year SIB, did not differ between the groups. It is important to note that small cell sizes for particular methods of SIB prohibited a more indepth analysis.

\section{Psychopathology}

The groups showed no differences on the SDQ dimensions of psychopathology, with the exception of emotional problems $\left(t_{(125)}=5.11, p<.0001\right)$ and SDQ total score respectively $\left.t_{(125)}=3.21, p=.002\right)$. As illustrated in Figure 2, adolescent inpatients reported greater emotional problems. When addressing differences between participants who reported lifetime SIB and those with no history of SIB within groups, our analyses revealed significant differences in psychiatric inpatients $\left(t_{(75)}=-4.00, p=.0001\right)$ and detainees $\left(t_{(48)}=-2.50\right.$, $p=.016)$. Further, among psychiatric patients, those reporting lifetime SIB reported greater conduct problems $\left(t_{(75)}=-2.04, p=.045\right)$. Those with a history of SIB also showed greater scores on the SDQ total score in inpatients $\left(t_{(75)}=-2.75, p=.007\right)$ and detainees $\left(t_{(48)}=-2.14, p=.037\right)$. The findings are illustrated in Figure 1.

\section{Borderline Personality Pathology}

The groups differed on all dimensions of borderline personality pathology, with the exception of insecure attachment, narcissism, and suspiciousness. The inpatients re-
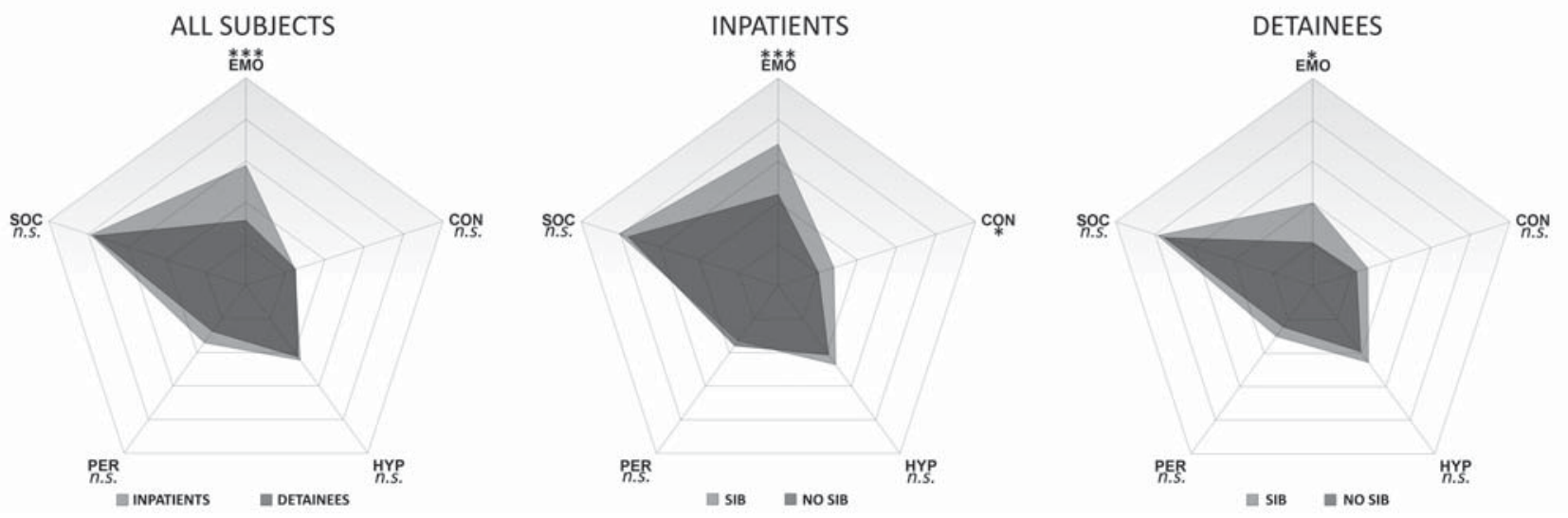

Figure 1. Psychopathological profile by group and lifetime self-injurious behavior. Illustrated are the subscales from the Strength and Difficulties Questionnaire (SDQ); EMO: emotional symptoms; CON: conduct problems; HYP: hyperactivity/inattention; PER: peer relationship problems; SOC: prosocial behavior. The significance levels derived from $t$-tests on group differences: ${ }^{* \star} p<.001 ; * \star p<.01 ; * p<.05 ; n$. s. $=$ not significant.
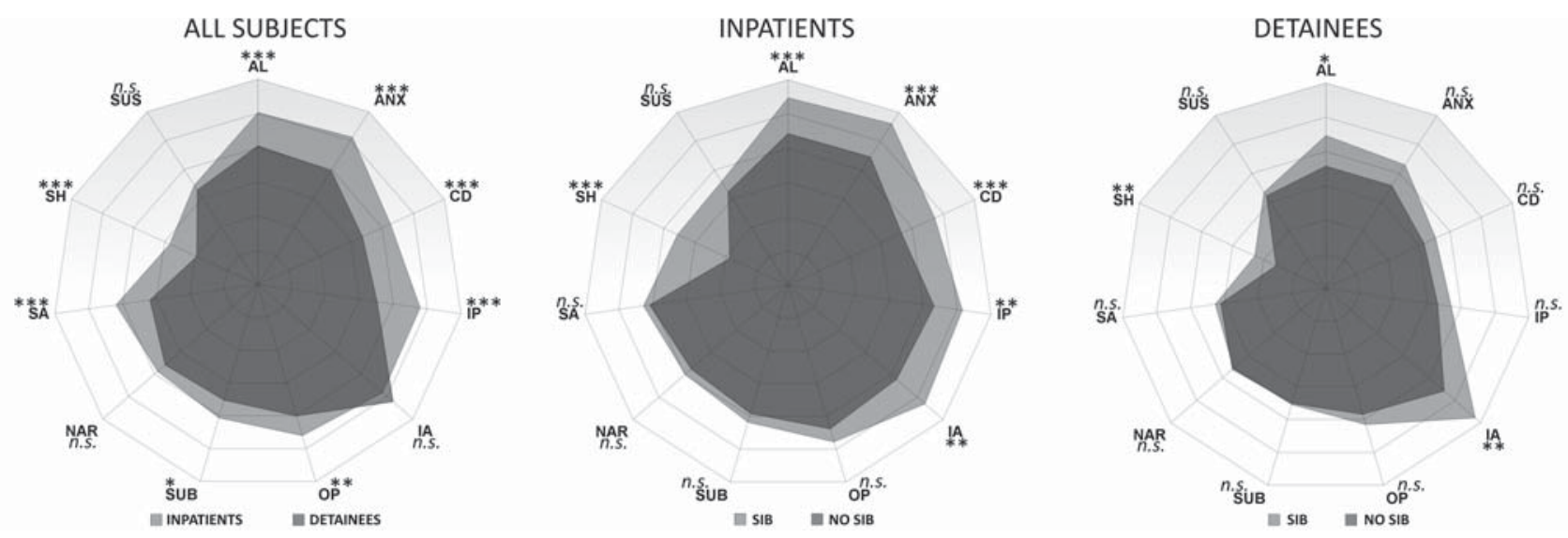

Figure 2. Personality pathology profile by group and lifetime self-injurious behavior. Illustrated are the subscales from the Dimensional Assessment of Personality Pathology - Basic Questionnaire (DAPP-BQ); AL: affective lability; ANX: anxiousness; CD: cognitive dysregulation; IP: identity problems; IA: insecure attachment; OP: oppositionality; SUB: submissiveness; NAR: narcissism ; SA: social avoidance; SH: self-harm; SUS: suspiciousness. The significance levels derived from $t$-tests on group differences: ${ }^{* \star} p<.001 ;{ }^{*} p<.01 ;{ }^{*} p<.05 ; n$. s. $=$ not significant. 
ported greater affective lability $\left(t_{(125)}=4.00, p<.0001\right)$, anxiousness $\left(t_{(125)}=4.40, p<.0001\right)$, cognitive dysregulation $\left(t_{(125)}=3.78, p<.0001\right)$, identity problems $\left(t_{(125)}=5.08\right.$, $p<.0001)$, oppositionality $\left(t_{(125)}=2.79, p=.006\right)$, submissiveness $\left(t_{(125)}=2.50, p=.014\right)$, social avoidance $\left(_{(125)}=4.01, p<.001\right)$, and obviously self-harm $t_{(125)}=3.80$, $p<.001)$. Comparisons of the participants with and without lifetime SIB by group revealed that inpatients $\left(t_{(75)}=-3.69, p<.001\right)$ and detainees $\left(t_{(48)}=-2.44, p=.019\right)$ with SIB reported greater affective lability. Similar, ratings on insecure attachment were greater in inpatients $\left(t_{(75)}=-3.16, p=.002\right)$ and detainees $\left(t_{(48)}=-2.78, p=.008\right)$ engaging in SIB. Anxiousness $\left(t_{(75)}=-3.77, p<.001\right)$, cognitive dysregulation $\left(t_{(75)}=-3.76, p<.001\right)$, identity problems $\left(t_{(75)}=-2.68, p=.009\right)$ only distinguished inpatients with and without lifetime SIB. Obviously, participants with lifetime SIB, independent of group, also reported greater self-harm on the DAPP. Findings are illustrated in Figure 2.

\section{Predictors of Lifetime Self-Injury}

Regarding general psychopathology, logistic regression analysis showed that only emotional symptoms and conduct problems were associated with lifetime SIB (Table 2). These associations held, even after controlling for sex and age, but were unspecific in predicting lifetime SIB in interaction with the respective group. With respect to the different domains of borderline personality pathology, affective lability, anxiousness, cognitive dysregulation, identity problems, and insecure attachment were associated with slightly increased odds for the endorse- ment of lifetime SIB, also after adjusting for sex and age. Again, none of the domains was specific in predicting lifetime SIB by group (Table 3). Sex was the strongest predictor of lifetime SIB in all models.

\section{Discussion}

The present study investigated differences and commonalities concerning borderline personality pathology and general psychopathology in adolescent psychiatric inpatients and detainees with a history of lifetime SIB. In contrast to our hypothesis, adolescent delinquents from a consecutive sample recruited at a youth detention unit reported a lifetime SIB prevalence of $54 \%$, which was comparable to that reported by psychiatric inpatients (57.1\%). The prevalence of lifetime SIB in the present sample of adolescent delinquents is slightly above the rates reported in a recent systematic review (Casiano et al., 2013) and about twice as high as those in a recent study from Switzerland (Lüdtke et al., 2017). However, the latter study included adolescents which had been either voluntarily placed in the respective youth welfare and juvenile justice institutions or by penal or civil law. In contrast, the lifetime prevalence of SIB among our consecutive sample of adolescent psychiatric inpatients fits well with previous data in comparable populations (Kaess et al., 2013). The groups showed significant differences with respect to the pastyear prevalence of SIB, suggesting that psychiatric inpatients endorse more recent SIB, as self-reports even outnumbered those for lifetime SIB in the respective group. A prevalence of SIB of around $14 \%$ in detainees within the

Table 2. Predictors of lifetime self-injurious behavior: Psychopathology. Dependent variable: life-time SIB (yes/no); unadjusted model: the model included the respective predictor (continuous score on the respective SDQ subscale), group (inpatients, detainees) and their interaction; adjusted model: the adjusted model further included sex (female/male) and the age of participants (continuous) as predictors; values represent odds ratios (OR) and their respective $95 \%$ confidence interval

\begin{tabular}{|c|c|c|c|c|c|c|c|c|}
\hline \multirow[b]{2}{*}{ SDQ subscale } & \multicolumn{3}{|c|}{ Unadjusted model } & \multicolumn{5}{|c|}{ Adjusted model } \\
\hline & Predictor & Group & Interaction & Predictor & Group & Interaction & Sex & Age \\
\hline $\begin{array}{l}\text { SDQ: } \\
\text { emotional symptoms }\end{array}$ & $\begin{array}{c}1.39 \\
{[1.15 ; 1.68]}\end{array}$ & $\begin{array}{c}2.56 \\
{[0.58 ; 11.30]}\end{array}$ & $\begin{array}{c}0.95 \\
{[0.70 ; 1.29]}\end{array}$ & $\begin{array}{c}1.26 \\
{[1.02 ; 1.56]}\end{array}$ & $\begin{array}{c}1.86 \\
{[0.39 ; 8.84]}\end{array}$ & $\begin{array}{c}1.00 \\
{[0.73 ; 1.37]}\end{array}$ & $\begin{array}{c}3.01 \\
{[1.25 ; 7.24]}\end{array}$ & $\begin{array}{c}0.94 \\
{[0.74 ; 1.21]}\end{array}$ \\
\hline $\begin{array}{l}\text { SDQ: } \\
\text { conduct problems }\end{array}$ & $\begin{array}{c}1.35 \\
{[1.00 ; 1.84]}\end{array}$ & $\begin{array}{c}1.21 \\
{[0.34 ; 0.27]}\end{array}$ & $\begin{array}{c}0.87 \\
{[0.56 ; 1.34]}\end{array}$ & $\begin{array}{c}1.43 \\
{[1.02 ; 2.00]}\end{array}$ & $\begin{array}{c}1.05 \\
{[0.26 ; 4.20]}\end{array}$ & $\begin{array}{c}0.92 \\
{[0.58 ; 1.47]}\end{array}$ & $\begin{array}{c}6.35 \\
{[2.79 ; 14.46]}\end{array}$ & $\begin{array}{c}1.08 \\
{[0.86 ; 1.36]}\end{array}$ \\
\hline $\begin{array}{l}\text { SDQ: } \\
\text { hyperactivity/inattention }\end{array}$ & $\begin{array}{c}1.01 \\
{[0.74 ; 1.38]}\end{array}$ & $\begin{array}{c}0.86 \\
{[0.19 ; 3.93]}\end{array}$ & $\begin{array}{c}1.11 \\
{[0.91 ; 1.36]}\end{array}$ & $\begin{array}{c}1.05 \\
{[0.85 ; 1.31]}\end{array}$ & $\begin{array}{c}0.50 \\
{[0.09 ; 2.77]}\end{array}$ & $\begin{array}{c}1.16 \\
{[0.82 ; 1.64]}\end{array}$ & $\begin{array}{c}5.69 \\
{[2.56 ; 12.66]}\end{array}$ & $\begin{array}{c}1.02 \\
{[0.81 ; 1.28]}\end{array}$ \\
\hline $\begin{array}{l}\text { SDQ: } \\
\text { peer relationship problems }\end{array}$ & $\begin{array}{c}0.95 \\
{[0.78 ; 1.16]}\end{array}$ & $\begin{array}{c}0.48 \\
{[0.13 ; 1.72]}\end{array}$ & $\begin{array}{c}1.23 \\
{[0.86 ; 1.76]}\end{array}$ & $\begin{array}{c}0.91 \\
{[0.73 ; 1.13]}\end{array}$ & $\begin{array}{c}0.52 \\
{[0.13 ; 2.08]}\end{array}$ & $\begin{array}{c}1.22 \\
{[0.81 ; 1.84]}\end{array}$ & $\begin{array}{c}5.38 \\
{[2.46 ; 11.77]}\end{array}$ & $\begin{array}{c}1.01 \\
{[0.80 ; 1.29]}\end{array}$ \\
\hline $\begin{array}{l}\text { SDQ: } \\
\text { prosocial behavior }\end{array}$ & $\begin{array}{c}1.13 \\
{[0.89 ; 1.42]}\end{array}$ & $\begin{array}{c}1.08 \\
{[0.05 ; 22.05]}\end{array}$ & $\begin{array}{c}0.98 \\
{[0.67 ; 1.42]}\end{array}$ & $\begin{array}{c}1.01 \\
{[0.78 ; 1.30]}\end{array}$ & $\begin{array}{c}1.29 \\
{[0.05 ; 33.63]}\end{array}$ & $\begin{array}{c}0.96 \\
{[0.64 ; 1.44]}\end{array}$ & $\begin{array}{c}5.44 \\
{[2.43 ; 12.21]}\end{array}$ & $\begin{array}{c}1.04 \\
{[0.83 ; 1.31]}\end{array}$ \\
\hline
\end{tabular}


Table 3. Predictors of lifetime self-injurious behavior: Personality pathology. Dependent variable: life-time SIB (yes/no); unadjusted model: the model included the respective predictor (continuous score on the respective DAPP subscale), group (inpatients, detainees) and their interaction; adjusted model: the adjusted model further included sex (female/male) and the age of participants (continuous) as predictors; values represent odds ratios (OR) and their respective $95 \%$ confidence interval

\begin{tabular}{|c|c|c|c|c|c|c|c|c|}
\hline \multirow[b]{2}{*}{ DAPP subscale* } & \multicolumn{3}{|c|}{ Unadjusted Model } & \multicolumn{5}{|c|}{ Adjusted model } \\
\hline & Predictor & Group & Interaction & Predictor & Group & Interaction & Sex & Age \\
\hline $\begin{array}{l}\text { DAPP: } \\
\text { affective lability }\end{array}$ & $\begin{array}{c}1.07 \\
{[1.03 ; 1.12]}\end{array}$ & $\begin{array}{c}2.98 \\
{[0.16 ; 54.22]}\end{array}$ & $\begin{array}{c}0.99 \\
{[0.93 ; 1.05]}\end{array}$ & $\begin{array}{c}1.05 \\
{[1.01 ; 1.10]}\end{array}$ & $\begin{array}{c}1.44 \\
{[0.07 ; 30.71]}\end{array}$ & $\begin{array}{c}1.00 \\
{[0.94 ; 1.07]}\end{array}$ & $\begin{array}{c}4.20 \\
{[1.85 ; 9.54]}\end{array}$ & $\begin{array}{c}0.98 \\
{[0.77 ; 1.25]}\end{array}$ \\
\hline $\begin{array}{l}\text { DAPP: } \\
\text { anxiousness }\end{array}$ & $\begin{array}{c}1.07 \\
{[1.03 ; 1.11]}\end{array}$ & $\begin{array}{c}5.25 \\
{[0.38 ; 72.81]}\end{array}$ & $\begin{array}{c}0.97 \\
{[0.92 ; 1.03]}\end{array}$ & $\begin{array}{c}1.05 \\
{[1.01 ; 1.10]}\end{array}$ & $\begin{array}{c}2.63 \\
{[0.16 ; 43.69]}\end{array}$ & $\begin{array}{c}0.99 \\
{[0.93 ; 1.05]}\end{array}$ & $\begin{array}{c}4.18 \\
{[1.85 ; 9.46]}\end{array}$ & $\begin{array}{c}0.93 \\
{[0.73 ; 1.20]}\end{array}$ \\
\hline $\begin{array}{l}\text { DAPP: } \\
\text { cognitive dysregulation }\end{array}$ & $\begin{array}{c}1.07 \\
{[1.03 ; 1.12]}\end{array}$ & $\begin{array}{c}7.02 \\
{[0.65 ; 75.93]}\end{array}$ & $\begin{array}{c}0.96 \\
{[0.90 ; 1.02]}\end{array}$ & $\begin{array}{c}1.06 \\
{[1.02 ; 1.11]}\end{array}$ & $\begin{array}{c}4.41 \\
{[0.34 ; 57.62]}\end{array}$ & $\begin{array}{c}0.97 \\
{[0.91 ; 1.04]}\end{array}$ & $\begin{array}{c}4.65 \\
{[2.08 ; 10.40]}\end{array}$ & $\begin{array}{c}1.00 \\
{[0.78 ; 1.27]}\end{array}$ \\
\hline $\begin{array}{l}\text { DAPP: } \\
\text { identity problems }\end{array}$ & $\begin{array}{c}1.05 \\
{[1.01 ; 1.08]}\end{array}$ & $\begin{array}{c}3.38 \\
{[0.31 ; 36.26]}\end{array}$ & $\begin{array}{c}0.98 \\
{[0.92 ; 1.03]}\end{array}$ & $\begin{array}{c}1.04 \\
{[1.00 ; 1.08]}\end{array}$ & $\begin{array}{c}2.83 \\
{[0.23 ; 35.41]}\end{array}$ & $\begin{array}{c}0.98 \\
{[0.93 ; 1.05]}\end{array}$ & $\begin{array}{c}5.03 \\
{[2.28 ; 11.09]}\end{array}$ & $\begin{array}{c}0.99 \\
{[0.78 ; 1.25]}\end{array}$ \\
\hline $\begin{array}{l}\text { DAPP: } \\
\text { insecure attachment }\end{array}$ & $\begin{array}{c}1.05 \\
{[1.02 ; 1.08]}\end{array}$ & $\begin{array}{c}0.58 \\
{[0.04 ; 8.48]}\end{array}$ & $\begin{array}{c}1.00 \\
{[0.95 ; 1.06]}\end{array}$ & $\begin{array}{c}1.04 \\
{[1.00 ; 1.07]}\end{array}$ & $\begin{array}{c}0.54 \\
{[0.03 ; 9.20]}\end{array}$ & $\begin{array}{c}1.01 \\
{[0.95 ; 1.06]}\end{array}$ & $\begin{array}{c}3.82 \\
{[1.68 ; 8.64]}\end{array}$ & $\begin{array}{c}0.98 \\
{[0.77 ; 1.24]}\end{array}$ \\
\hline $\begin{array}{l}\text { DAPP: } \\
\text { oppositionality }\end{array}$ & $\begin{array}{c}1.03 \\
{[0.99 ; 1.08]}\end{array}$ & $\begin{array}{c}1.94 \\
{[0.13 ; 29.79]}\end{array}$ & $\begin{array}{c}0.99 \\
{[0.93 ; 1.05]}\end{array}$ & $\begin{array}{c}1.05 \\
{[1.00 ; 1.10]}\end{array}$ & $\begin{array}{c}3.32 \\
{[0.17 ; 64.11]}\end{array}$ & $\begin{array}{c}0.98 \\
{[0.91 ; 1.04]}\end{array}$ & $\begin{array}{c}6.22 \\
{[2.76 ; 14.00]}\end{array}$ & $\begin{array}{c}1.01 \\
{[0.80 ; 1.28]}\end{array}$ \\
\hline $\begin{array}{l}\text { DAPP: } \\
\text { submissiveness }\end{array}$ & $\begin{array}{c}1.02 \\
{[0.98 ; 1.06]}\end{array}$ & $\begin{array}{c}1.80 \\
{[0.16 ; 20.05]}\end{array}$ & $\begin{array}{c}0.98 \\
{[0.92 ; 1.05]}\end{array}$ & $\begin{array}{c}1.00 \\
{[0.96 ; 1.05}\end{array}$ & $\begin{array}{c}1.49 \\
{[0.11 ; 20.38]}\end{array}$ & $\begin{array}{c}0.99 \\
{[0.92 ; 1.06]}\end{array}$ & $\begin{array}{c}5.40 \\
{[2.44 ; 11.93]}\end{array}$ & $\begin{array}{c}1.06 \\
{[0.83 ; 1.34]}\end{array}$ \\
\hline $\begin{array}{l}\text { DAPP: } \\
\text { narcissism }\end{array}$ & $\begin{array}{c}1.01 \\
{[0.98 ; 1.05]}\end{array}$ & $\begin{array}{c}1.70 \\
{[0.20 ; 14.78]}\end{array}$ & $\begin{array}{c}0.98 \\
{[0.93 ; 1.04]}\end{array}$ & $\begin{array}{c}1.02 \\
{[0.98 ; 1.06]}\end{array}$ & $\begin{array}{c}1.74 \\
{[0.16 ; 18.69]}\end{array}$ & $\begin{array}{c}0.98 \\
{[0.93 ; 1.05]}\end{array}$ & $\begin{array}{c}5.54 \\
{[2.53 ; 12.11]}\end{array}$ & $\begin{array}{c}1.03 \\
{[0.82 ; 1.30]}\end{array}$ \\
\hline $\begin{array}{l}\text { DAPP: } \\
\text { social avoidance }\end{array}$ & $\begin{array}{c}1.01 \\
{[0.98 ; 1.04]}\end{array}$ & $\begin{array}{c}0.98 \\
{[0.13 ; 7.58]}\end{array}$ & $\begin{array}{c}1.0 \\
{[0.95 ; 1.05]}\end{array}$ & $\begin{array}{c}1.00 \\
{[0.97 ; 1.04]}\end{array}$ & $\begin{array}{c}0.97 \\
{[0.10 ; 9.10]}\end{array}$ & $\begin{array}{c}1.00 \\
{[0.94 ; 1.06]}\end{array}$ & $\begin{array}{c}5.32 \\
{[2.44 ; 11.60]}\end{array}$ & $\begin{array}{c}1.04 \\
{[0.82 ; 1.32]}\end{array}$ \\
\hline $\begin{array}{l}\text { DAPP: } \\
\text { suspiciousness }\end{array}$ & $\begin{array}{c}1.03 \\
{[0.99 ; 1.08]}\end{array}$ & $\begin{array}{c}1.81 \\
{[0.19 ; 17.24]}\end{array}$ & $\begin{array}{c}0.98 \\
{[0.92 ; 1.04]}\end{array}$ & $\begin{array}{c}1.03 \\
{[0.98 ; 1.08}\end{array}$ & $\begin{array}{c}1.64 \\
{[0.14 ; 19.48]}\end{array}$ & $\begin{array}{c}.98 \\
{[0.92 ; 1.06]}\end{array}$ & $\begin{array}{c}5.38 \\
{[2.47 ; 11.74]}\end{array}$ & $\begin{array}{c}1.04 \\
{[0.83 ; 1.31]}\end{array}$ \\
\hline
\end{tabular}

*excluding the DAPP subscale self-harm

past year fits quite well with previous studies among prisoners (Kenny et al., 2008). Adolescents from the inpatient sample also endorsed greater lifetime suicidal thoughts and behavior compared to adolescent detainees.

As to the level of general psychopathology between the groups, we found differences only with respect to emotional problems. The inpatients from the present sample reported greater emotional symptoms than the detainees. Most interestingly, we found considerable similarities when investigating differences among subsamples of adolescents with a lifetime history of SIB by group. Independent of the group, adolescents with a lifetime history of SIB endorsed greater emotional symptoms, compared to their nonlifetime SIB counterparts. Adolescent inpatients with lifetime SIB further differed with respect to the extent of conduct problems. Taken together, these findings suggest that psychiatric inpatients report greater emotional distress, independent of the group, is associated with lifetime SIB. Regression models further support this notion, given that emotional symptoms and conduct problems remained the only predictors of lifetime SIB independent of adjustments for age and sex and independent of the group. This finding is in line with previous studies addressing psychopathology associated with NSSI in adolescents in youth-welfare and juvenile-justice homes. However, while previous studies (Lüdtke et al., 2017) - somewhat surprisingly - found this association to be sex-specific (i.e., affective disorders only in boys, conduct disorders only in girls), we found emotional symptoms and conduct problems to predict lifetime SIB independent of sex. Again, given that the former study from Switzerland was not restricted to delinquent adolescents, the differences might be attributable to differences in samples and recruitment strategies.

Borderline personality pathology showed marked differences between groups on all domains assessed, with the exception of insecure attachment, narcissism, and submissiveness. The psychiatric inpatients endorsed greater difficulties on all respective domains of borderline personality pathology. Profiles of borderline personality by subgroups, comparing adolescents with lifetime SIB and those with no lifetime SIB among detainees and inpatients, showed an overall similar pattern, albeit with slight differences. Those 
with lifetime SIB were characterized by greater affective lability and insecure attachment independent of the group. Among inpatients, anxiousness, cognitive dysregulation, and identity problems further distinguished adolescents with lifetime SIB from their nonlifetime SIB counterparts. Overall, odds ratios for dimensions of borderline personality pathology in predicting lifetime SIB were considerably smaller than those obtained for general psychopathology. None of the domains of borderline personality pathology specifically predicted lifetime SIB by group.

Emotional symptoms and conduct problems seem to be common in those reporting lifetime SIB. The empirical evidence reveals that BPD and disruptive behavior disorders (i.e., oppositional defiant disorder, ODD, and conduct disorder, CD) are frequently comorbid (Ha et al., 2014), and longitudinal studies illustrate that ODD during childhood is a strong predictor of BPD in early adulthood (Burke \& Stepp, 2012; Helgeland et al. 2005) - in particular in males who may then end up in the juvenile legal system (Andrulonis, 1990). Adding to the present findings, future studies (including a formal diagnostic assessment of ODD and $\mathrm{CD}$ in adolescent detainees) need to disentangle the association of disruptive behavior disorders with BPD and lifetime SIB and explore different developmental trajectories resulting either in the presentation within the professional healthcare or justice system.

More broadly, in line with existing evidence, the present findings highlight the co-occurrence of delinquency and psychiatric symptoms in adolescent detainees and echo the call for interdisciplinary care for affected individuals (Underwood \& Washington, 2016). This includes regular assessments by mental health professionals with potential implications for subsequent treatment and prevention to address the underlying pathology and buffer potential detrimental effects of detention. Albeit, nationally and internationally (i.e. in the US) many facilities conduct regular mental-health screenings (Pajer et al., 2007), indicated and specialized care in Germany does not seem to meet the existing demand (e.g. Huchzermeier et al. 2016). Adolescent detainees with borderline personality pathology and SIB may benefit from interdisciplinary approaches promoting specialized treatment, much as personnel within the youth justice system may benefit from professional exchange with experienced colleagues within the mentalhealthcare system and vice versa.

In line with existing evidence, the present findings highlight the utility of SIB as a valid indicator for identifying adolescents with psychopathology, those at risk of developing severe psychopathology, and those engaging in suicidal behavior (Koenig et al., 2017). Most importantly, this holds true regardless of the setting (i.e., clinic or detention unit). Institutions within the juvenile justice setting, just like schools (Berger et al. 2015), should emphasize the in- dicative nature of SIB and develop best-practice approaches to risk-behavior screening to identify adolescents with mental health problems (Kaess et al., 2014), in order to gain confidence in approaching adolescents engaging in SIB to enable early intervention and appropriate care in line with existing clinical guidelines (Plener et al., 2016).

To summarize, lifetime SIB among adolescent psychiatric inpatients and detainees is associated with similar underlying patterns of psychopathology and borderline personality pathology. Surprisingly, psychopathological concomitants of the behavior did not differ between groups. On the group level, adolescent psychiatric inpatients endorsed greater psychopathological distress. However, in contrast to their respective nonlifetime SIB counterparts, adolescents endorsing lifetime SIB are characterized by similar patterns across domains of psycho- and borderline personality pathology.

The study has several limitations that need to be addressed and recommendations for future research can be given. First, the present study relied exclusively on selfreports of psychopathology and borderline personality pathology. While structured clinical interviews were conducted in psychiatric inpatients within routine clinical care (data not shown), self-reports were more feasible with respect to existing restrictions in the justice setting. Future studies would do well to extend the assessment of psychopathology and borderline personality disorders using structured clinical interviews. Second, while we assessed lifetime SIB and SIB in the past, we did not assess SIB occurring during the stay at the hospital or within the detention unit. The relative prevalence of SIB related to the respective research setting would have been informative to adjusting our analysis for environmental factors associated with SIB. Third, although we recruited consecutive samples and carefully matched detainees participating in the study to the expected sample of adolescent inpatients, the groups differed in age. In order to overcome this limitation, regression analysis on predictors of lifetime SIB were adjusted for age. On a different note, while we adjusted the respective analyses for age and sex, it is possible that other variables (i.e., socioeconomic status, education) that were not controlled for influenced the findings. Strengths of the study include a relative large sample size of psychiatric inpatients and detainees with a close to equally balanced sex ratio. Future studies would do well to address state-dependent distress associated with SIB during the time of detention/hospitalized care. Finally, we recruited participants from two study sites and different settings to address differences between adolescent psychiatric inpatients and detainees. However, there are marked regional and institutional differences in both the child and adolescent psychiatric and the detention setting. Future large-scaled multicenter studies are neces- 
sary to address the degree to which the present findings generalize to different youth justice (i.e., juvenile prison, closed youth centers) and mental-health settings.

\section{Conclusion}

The prevalence of lifetime SIB among adolescent psychiatric inpatients and delinquent adolescents detained within the youth justice system is comparable. SIB within the past year is more frequently endorsed by psychiatric inpatients in this age group. Psychiatric inpatients also report greater psychopathological distress and borderline personality pathology, suggesting that, in contrast to adolescent detainees, the group is characterized by more immediate and acute symptoms. However, we were unable to identify particular patterns of psychopathology and borderline personality pathology in predicting lifetime SIB that distinguished inpatients from detainees. Findings suggest universal facets of psychopathology and borderline personality pathology associated with lifetime SIB. Further, the findings highlight the need for child and adolescent psychiatric care within the youth justice system and call for interdisciplinary collaboration.

\section{Acknowledgments}

Julian Koenig is supported by a Physician-Scientist Fellowship provided by the Medical School, University of Heidelberg, Germany.

\section{References}

American Psychiatric Association. (2013). Diagnostic and statistical manual of mental disorders (5th ed.). Arlington, VA: American Psychiatric Publishing.

Andrulonis, P.A. (1990). Disruptive behavior disorders in boys and the borderline personality disorder in men. Annals of Clinical Psychiatry, 3(1), 23-26.

Asarnow, J.R., Porta, G., Spirito, A., Emslie, G., Clarke, G., Wagner, K.D., ... Brent, D.A. (2011). Suicide attempts and nonsuicidal self-injury in the treatment of resistant depression in adolescents: findings from the TORDIA study. Journal of the American Academy of Child and Adolescent Psychiatry, 50, 772-781. doi 10.1016/j.jaac.2011.04.003.

Auerbach, R. P., Kim, J.C., Chango, J.M., Spiro, W.J., Cha, C., Gold, J., ... Nock, M.K. (2014). Adolescent nonsuicidal self-injury: Examining the role of child abuse, comorbidity, and disinhibition. Psychiatry Research, 220,579-584. doi 10.1016/j.psychres.2014.07.027.

Berger, E., Hasking, P., Reupert, A. (2015). Developing a policy to address nonsuicidal self-injury in schools. Journal of School Health, 85, 629-647. doi 10.1111/josh.12292.

Brunner, R., Kaess, M., Parzer, P., Fischer, G., Carli, V., Hoven, C. W., ... Wasserman, D. (2014). Life-time prevalence and psychosocial correlates of adolescent direct self-injurious behavior: A comparative study of findings in 11 European countries. Journal of Child Psychology and Psychiatry, and Allied Disciplines, 55, 337348. doi 10.1111/jcpp.12166.

Burke, J.D., Stepp, S.D. (2012). Adolescent disruptive behavior and borderline personality disorder symptoms in young adult men. Journal of Abnormal Child Psychology, 40, 35-44. doi 10.1007\%2Fs10802-011-9558-7.

Carli, V., Jovanović, N., Podlesek, A., Roy, A., Rihmer, Z., Maggi, S., ... Sarchiapone, M. (2010). The role of impulsivity in self-mutilators, suicide ideators and suicide attempters: A study of 1265 male incarcerated individuals. Journal of Affective Disorders, 123, 116-122. doi 10.1016/j.jad.2010.02.119.

Carli, V., Mandelli, L., Poštuvan, V., Roy, A., Bevilacqua, L., Cesaro, C., ... Sarchiapone, M. (2011, March). Self-harm in prisoners. Retrieved from /core/journals/cns-spectrums/article/selfharmin-prisoners/A0958DB662FC5698B892FEF0D0DA379D.

Casiano, H., Katz, L.Y., Globerman, D., \& Sareen, J. (2013). Suicide and deliberate self-injurious behavior in juvenile correctional facilities: A review. Journal of the Canadian Academy of Child and Adolescent Psychiatry, 22, 118-124.

Chowanec, G.D., Josephson, A. M., Coleman, C., \& Davis, H. (1991). Self-harming behavior in incarcerated male delinquent adolescents. Journal of the American Academy of Child and Adolescent Psychiatry, 30, 202-207. doi 10.1097/00004583-19910300000007.

Dixon-Gordon, K., Harrison, N., \& Roesch, R. (2012). Nonsuicidal self-injury within offender populations: A systematic review. International Journal of Forensic Mental Health, 11(1), 33-50. doi 10.1080/14999013.2012.667513.

Esposito, C., Spirito, A., Boergers, J., \& Donaldson, D. (2003). Affective, behavioral, and cognitive functioning in adolescents with multiple suicide attempts. Suicide and Life-Threatening Behavior, 33, 389-399.

Fazel, S., Doll, H., \& Långström, N. (2008). Mental disorders among adolescents in juvenile detention and correctional facilities: A systematic review and metaregression analysis of 25 surveys. Journal of the American Academy of Child and Adolescent Psychiatry, 47, 1010-1019. doi 10.1097/CHI.Ob013e 31817 eecf3

Fazel, S., Hayes, A.J., Bartellas, K., Clerici, M., \& Trestman, R. (2016). The mental health of prisoners: A review of prevalence, adverse outcomes and interventions. The Lancet. Psychiatry, 3, 871-881. doi 10.1016/S2215-0366(16)30142-0.

Fazel, S., \& Seewald, K. (2012). Severe mental illness in 33588 prisoners worldwide: Systematic review and meta-regression analysis. The British Journal of Psychiatry, 200, 364-373. doi 10.1192/bjp.bp.111.096370.

Fliege, H., Lee, J.-R., Grimm, A., \& Klapp, B.F. (2009). Risk factors and correlates of deliberate self-harm behavior: A systematic review. Journal of Psychosomatic Research, 66, 477-493. doi 10.1016/j.jpsychores.2008.10.013.

Goodman, R. (1997). The Strengths and Difficulties Questionnaire: A research note. Journal of Child Psychology and Psychiatry, and Allied Disciplines, 38, 581-586.

Guertin, T., Lloyd-Richardson, E., Spirito, A., Donaldson, D., \& Boergers, J. (2001). Self-mutilative behavior in adolescents who attempt suicide by overdose. Journal of the American Academy of Child and Adolescent Psychiatry, 40, 1062-1069. doi 10.1097/00004583-200109000-00015.

Ha, C., Balderas, J.C., Zanarini, M.C., Oldham, J., Sharp, C. (2014). Psychiatric comorbidity in hospitalized adolescents with borderline personality disorder. Journal of Clinical Psychiatry, 75, e457-64. doi 10.4088/JCP.13m08696.

Hawton, K., \& Harriss, L. (2007). Deliberate self-harm in young people: Characteristics and subsequent mortality in a 20-year 
cohort of patients presenting to hospital. The Journal of Clinical Psychiatry, 68, 1574-1583.

Hawton, K., Linsell, L., Adeniji, T., Sariaslan, A., \& Fazel, S. (2014). Self-harm in prisons in England and Wales: An epidemiological study of prevalence, risk factors, clustering, and subsequent suicide. Lancet (London, UK), 383(9923), 1147-1154. doi 10.1016/ S0140-6736(13)62118-2.

Hawton, K., Saunders, K., Topiwala, A., \& Haw, C. (2013). Psychiatric disorders in patients presenting to hospital following selfharm: A systematic review. Journal of Affective Disorders, 151, 821-830. doi 10.1016/j.jad.2013.08.020.

Helgeland, M. I., Kjelsberg, E., Torgersen, S. (2005). Continuities between emotional and disruptive behavior disorders in adolescence and personality disorders in adulthood. The American Journal of Psychiatry, 162, 1941-1947. doi 10.1176/appi.ajp. 162.10.1941.

Huchzermeier, C., Schulte-Ostermann, M.A., Folgmann, S. (2016). Neues aus der Anstalt: Die "psychiatrische Sprechstunde" in der JVA Neumünster - Minimalversorgung psychischer Störungen [The psychiatric office hours in the Neumünster Prison. Basic treatment of mental disorders]. Rechtspsychologie, 2, 190205. doi 10.5771/2365-1083-2016-2-190.

Kaess, M., Brunner, R., Parzer, P., Carli, V., Apter, A., Balazs, J.A., ... Wasserman, D. (2014). Risk-behavior screening for identifying adolescents with mental health problems in Europe. European Child and Adolescent Psychiatry, 23, 611-620. doi 10.1007/ s00787-013-0490-y.

Kaess, M., Brunner, R., Parzer, P., Edanackaparampil, M., Schmidt, J., Kirisgil, M., ... Resch, F. (2016). Association of adolescent dimensional borderline personality pathology with past and current nonsuicidal self-injury and lifetime suicidal behavior: A clinical multicenter study. Psychopathology. doi 10.1159/000448481.

Kaess, M., Parzer, P., Mattern, M., Plener, P.L., Bifulco, A., Resch, F., \& Brunner, R. (2013). Adverse childhood experiences and their impact on frequency, severity, and the individual function of nonsuicidal self-injury in youth. Psychiatry Research, 206, 265272. doi 10.1016/j.psychres.2012.10.012.

Kaess, M., Parzer, P., Mattern, M., Resch, F., Bifulco, A., und Brunner, R. (2011). Childhood Experiences of Care and Abuse (CECA): Validierung der deutschen Version von Fragebogen und korrespondierendem Interview sowie Ergebnisse einer Untersuchung von Zusammenhängen belastender Kindheitserlebnisse mit suizidalen Verhaltensweisen. [Childhood Experiences of Care and Abuse (CECA): Validation of the German version of the questionnaire and interview, and results of an investigation of correlations between adverse childhood experiences and suicidal behavior]. Zeitschrift für Kinder- und Jugendpsychiatrie und Psychotherapie, 39, 243-252. doi 10.1024/14224917/a000115.

Kenny, D., Lennings, C., \& Munn, O. (2008). Risk factors for selfharm and suicide in incarcerated young offenders: Implications for policy and practice. Journal of Forensic Psychology Practice, 8, 358-382. doi 10.1080/15228930802199317.

Kirchner, T., Forns, M., \& Mohíano, S. (2008). Identifying the risk of deliberate self-harm among young prisoners by means of coping typologies. Suicide and Life-Threatening Behavior, 38, 442448. doi 10.1521/suli.2008.38.4.442.

Koenig, J., Brunner, R., Fischer-Waldschmidt, G., Parzer, P., Plener, P.L., Park, J., ... Kaess, M. (2017). Prospective risk for suicidal thoughts and behavior in adolescents with onset, maintenance or cessation of direct self-injurious behavior. European Child and Adolescent Psychiatry, 26, 345-354. doi 10.1007/s00787016-0896-4.

Krischer, M.K., Pukrop, R., Halstenberg, A., Lehmkuhl, G., \& Sevecke, K. (2012). Stabilität von Persönlichkeitspathologie bei jugendlichen Delinquenten [Stability of personality pathology in adolescent delinquents]. Kindheit und Entwicklung, 21, 151160. doi 10.1026/0942-5403/a000081.

Krischer, M.K., Sevecke, K., Lehmkuhl, G., \& Pukrop, R. (2007). Dimensional assessment of personality pathology in female and male juvenile delinquents. Journal of Personality Disorders, 21, 675-689. doi 10.1521/pedi.2007.21.6.675.

Livesley, W.J., \& Jackson, D. N. (2009). Manual for the Dimensional Assessment of Personality Pathology-Basic Questionnaire. Port Huron, MI: Sigma Press.

Lloyd, E., Kelley, M., \& Hope, T. (1997). Self-mutilation in a community sample of adolescents: descriptive characteristics and provisional prevalence rates. Poster Session at the Annual Meeting of the Society for Behavioral Medicine, New Orleans, LA.

Lloyd-Richardson, E.E., Perrine, N., Dierker, L., \& Kelley, M.L. (2007). Characteristics and functions of nonsuicidal self-injury in a community sample of adolescents. Psychological Medicine, 37,1183-1192. doi 10.1017/S003329170700027X.

Lüdtke, J., In-Albon, T., Schmeck, K., Plener, P.L., Fegert, J.M., \& Schmid, M. (2017). Nonsuicidal self-injury in adolescents placed in youth welfare and juvenile justice group homes: Associations with mental disorders and suicidality. Journal of Abnormal Child Psychology, 1-12. doi 10.1007/s10802-017-0291-8.

Madge, N., Hawton, K., McMahon, E.M., Corcoran, P., De Leo, D., de Wilde, E.J., ... Arensman, E. (2011). Psychological characteristics, stressful life events and deliberate self-harm: Findings from the Child \& Adolescent Self-Harm in Europe (CASE) Study. European Child and Adolescent Psychiatry, 20, 499-508. doi 10.1007/s00787-011-0210-4.

Matsumoto, T., Yamaguchi, A., Chiba, Y., Asami, T., Iseki, E., \& Hirayasu, Y. (2005). Self-burning versus self-cutting: Patterns and implications of self-mutilation. A preliminary study of differences between self-cutting and self-burning in a Japanese juvenile detention center. Psychiatry and Clinical Neurosciences, 59,62-69. doi 10.1111/j.1440-1819.2005.01333.x.

Muehlenkamp, J.J., Claes, L., Havertape, L., \& Plener, P.L. (2012). International prevalence of adolescent nonsuicidal self-injury and deliberate self-harm. Child and Adolescent Psychiatry and Mental Health, 6, 10. doi 10.1186/1753-2000-6-10.

Müller, A., Claes, L., Smits, D., Brähler, E., \& Zwaan, M. de. (2016). Prevalence and correlates of self-harm in the German general population. PLOS ONE, 11, e0157928. doi 10.1371/journal. pone.0157928.

Pajer, K.A., Kelleher, K., Gupta, R.A., Rolls, J., Gardner, W. (2007). Psychiatric and medical health care policies in juvenile detention facilities. Journal of the American Academy of Child and Adolescent Psychiatry, 46, 1660-1667. doi 10.1097/chi.0b013e318157d2da.

Paykel, E.S., Myers, J.K., Lindenthal, J.J., \& Tanner, J. (1974). Suicidal feelings in the general population: a prevalence study. The British Journal of Psychiatry: The Journal of Mental Science, 124, 460-469.

Penn, J.V., Esposito, C.L., Schaeffer, L.E., Fritz, G.K., \& Spirito, A. (2003). Suicide attempts and self-mutilative behavior in a juvenile correctional facility. Journal of the American Academy of Child and Adolescent Psychiatry, 42, 762-769. doi 10.1097/01. $\mathrm{CHI} .0000046869 .56865 .46$.

Plener, P. L., Allroggen, M., Kapusta, N. D., Brähler, E., Fegert, J. M., \& Groschwitz, R.C. (2016). The prevalence of nonsuicidal self-Injury (NSSI) in a representative sample of the German population. BMC Psychiatry, 16. doi 10.1186/s12888-016-1060-x.

Plener, P.L., Brunner, R., Fegert, J.M., Groschwitz, R., In-Albon, T., Kaess, M., ... Becker, K. (2016). Treating nonsuicidal self-injury (NSSI) in adolescents: Consensus-based German guidelines. Child and Adolescent Psychiatry Mental Health, 10, 46. doi 10.1186\%2Fs13034-016-0134-3.

Prinstein, M.J., Nock, M. K., Simon, V., Aikins, J.W., Cheah, C.S. L., \& Spirito, A. (2008). Longitudinal trajectories and predictors of 
adolescent suicidal ideation and attempts following inpatient hospitalization. Journal of Consulting and Clinical Psychology, 76, 92-103. doi 10.1037/0022-006X.76.1.92.

Pukrop, R. (2002). Dimensional personality profiles of borderline personality disorder in comparison with other personality disorders and healthy controls. Journal of Personality Disorders, 16, 135-147.

Pukrop, R., Gentil, I., Steinbring, I., \& Steinmeyer, E. (2001). Factorial structure of the German version of the Dimensional Assessment of Personality Pathology-Basic Questionnaire in clinical and nonclinical samples. Journal of Personality Disorders, 15, 450-456. doi 10.1521/pedi.15.5.450.19195.

Radeloff, D., Lempp, T., Rauf, A., Bennefeld-Kersten, K., Kettner, M. \& Freitag, C.M. (2016). Suizid und Suizidalität unter adoleszenten Häftlingen. [Suicide and suicide tendencies in adolescent detainees]. Zeitschrift für Kinder- und Jugendpsychiatrie und Psychotherapie, 44, 9-20.

Roe-Sepowitz, D. (2007). Characteristics and predictors of selfmutilation: a study of incarcerated women. Criminal Behaviour and Mental Health, 17, 312-321. doi 10.1002/cbm.665.

Sahlin, H., Kuja-Halkola, R., Bjureberg, J., Lichtenstein, P., Molero, Y., Rydell, M., ... Hellner, C. (2017). Association between deliberate self-harm and violent criminality. JAMA Psychiatry. doi 10.1001/jamapsychiatry.2017.0338.

Swannell, S.V., Martin, G. E., Page, A., Hasking, P., \& St John, N.J. (2014). Prevalence of nonsuicidal self-injury in nonclinical samples: Systematic review, meta-analysis and meta-regression. Suicide and Life-Threatening Behavior, 44, 273-303. doi 10.1111/sltb.12070.

Tang, J., Yu, Y., Wu, Y., Du, Y., Ma, Y., Zhu, H., ... Liu, Z. (2011). Association between nonsuicidal self-injuries and suicide attempts in Chinese adolescents and college students: A cross-section study. PloS One, 6, e17977. doi 10.1371/journal.pone.0017977.

Thomassin, K., Quint, E., Sezlik, S., \& Shaffer, A. (2017). Profiles of emotion deficits and adolescent nonsuicidal self-injury in an inpatient sample. Journal of Research on Adolescence. doi 10.1111/jora.12312.
Tromp, N.B., \& Koot, H.M. (2008). Dimensions of personality pathology in adolescents: Psychometric properties of the DAPPBQ-A. Journal of Personality Disorders, 22, 623-638. doi 10.1521/pedi.2008.22.6.623.

UK Ministry of Justice. (2015). Safety in custody quarterly update to September 2015 - GOV.UK. Retrieved from https://www.gov. uk/government/statistics/safety-in-custody-quarterly-updateto-september-2015.

Underwood, L.A., Washington, A. (2016). Mental illness and juvenile offenders. International Journal of Environmental Research and Public Health, 13, 228 doi 10.3390\%2Fijerph13020228.

Wilkinson, P., Kelvin, R., Roberts, C., Dubicka, B., \& Goodyer, I. (2011). Clinical and psychosocial predictors of suicide attempts and nonsuicidal self-injury in the Adolescent Depression Antidepressants and Psychotherapy Trial (ADAPT). The American Journal of Psychiatry, 168, 495-501. doi 10.1176/appi.ajp.2010.10050718.

World Health Organization. (2014). Retrieved from http://apps. who.int/adolescent/second-decade/files/1612_MNCAH_ HWA_Executive_Summary.pdf.

Zetterqvist, M. (2015). The DSM-5 diagnosis of nonsuicidal self-injury disorder: A review of the empirical literature. Child and Adolescent Psychiatry and Mental Health, 9. doi 10.1186/s13034015-0062-7.

Submitted: 21.04.2017

Accepted after revision: 23.08.2017

There are no conflicts of interest.

Published online: 27.10.2017

\section{Prof Dr. Michael Kaess}

University Hospital of Child and Adolescent Psychiatry and Psychotherapy University of Bern

Bolligenstrasse 141c

3000 Bern 60

Switzerland

michael.kaess@upd.ch 